This item was submitted to Loughborough's Research Repository by the author.

Items in Figshare are protected by copyright, with all rights reserved, unless otherwise indicated.

\title{
A comparison of batteries for the MECS project
}

PLEASE CITE THE PUBLISHED VERSION

https://mecs.org.uk/downloads/a-comparison-of-batteries-for-the-mecs-project/

VERSION

VoR (Version of Record)

LICENCE

CC BY-NC-ND 4.0

REPOSITORY RECORD

Barton, John, Nigel Monk, and Richard Blanchard. 2019. "A Comparison of Batteries for the MECS Project". Loughborough University. https://hdl.handle.net/2134/12959897.v1. 


\section{A Comparison of Batteries for the MECS Project}

Author:

Author Affiliation:

Status:

Version:

Location:
Dr John Barton, Dr Nigel Monk, Dr Richard Blanchard

Centre for Renewable Energy Systems Technology (CREST), Loughborough University

Final

1.0

Wolfson School shared workspace, MECS_Technical folder 


\section{Introduction}

Three different batteries of different chemistries and different design have been purchased and tested for use with efficient electric cooking appliances. These are:

1. Lithium iron phosphate (LiFePO4, also known as LFP).

2. Valve-Regulated Lead Acid (VRLA). These units were manufactured by Yuasa.

3. Lead-Carbon, which is like lead-acid but with reported higher tolerance to deep cycling. These units were manufactured by Leoch.

In the context of the MECS project, the batteries are required to operate cooking appliances. In offgrid applications they are needed to store solar PV electricity. In weak-grid or mini-grid applications, batteries are needed to store electricity for later use, when grid electricity is more expensive, insufficiently powerful, or unavailable.

All the batteries tested have a nominal capacity of $100 \mathrm{Ah}$ and a nominal voltage of $12 \mathrm{~V}$. In the case of lead-carbon, a single 100Ah battery was used. In the case of VRLA and LiFePO4, two 50Ah batteries of each were used to make a total of 100Ah when connected in parallel. See Appendix for details of specific batteries.

\section{Battery Characteristics Important to the MECS Project Useful Energy Capacity}

All three batteries have a nominal capacity of $100 \mathrm{Ah}$ and voltage of $12 \mathrm{~V}$, making an energy capacity of $1.2 \mathrm{kWh}$. However, this reported capacity is available by slow discharge over 10 hours (C/10 rate).

Even in the most efficient cooking appliances available, the required capacity is at least $0.1 \mathrm{kWh}$ per litre of water or equivalent to be heated from ambient temperature to boiling point. Sometimes the energy required is significantly greater than this. A realistic useful energy capacity would be enough to heat 5 litres of water per day. With heat loss, thermal capacity of the cooking device and conversion losses, a useful energy capacity would be about $0.7 \mathrm{kWh}$ per day.

\section{Useful Power Rating}

The nominal energy capacity of a battery is available under ideal conditions, in a new battery. The example discharge rate quoted above, $\mathrm{C} / 10$, would give the batteries an energy capacity of $1.2 \mathrm{kWh}$. However, this discharge rate would provide a power of just $120 \mathrm{~W}$.

For the purposes of the MECS project, the ideal power rating would be over $1 \mathrm{~kW}$. The tested electric pressure cookers (EPCS) have power ratings of about $1 \mathrm{~kW}$. Most electric hotplates have power ratings of $1 \mathrm{~kW}$ to $2 \mathrm{~kW}$. Given that the cost of a battery-electric cooking system is strongly driven by the power rating, an acceptable electric power is approximately $700 \mathrm{~W}$, or $500 \mathrm{~W}$ at minimum.

The power available from a battery reduces as its charge is depleted. Therefore, under high-power discharge, the voltage collapses sooner than under low-power discharge, and the effective available energy is reduced at high power. Furthermore, batteries are degraded by total cycles used, by power draw and by depth of discharge.

In the design of an electric cooking system, there is compromise and trade-off between energy capacity, power rating, cost and longevity of the battery. 


\section{Internal Resistance}

The internal resistance determines the voltage rise or drop at the battery terminals for a given current injected or drawn from the battery respectively. It is important in determining the energy lost within the battery itself when charging or discharging. In the experiments conducted to date, only the discharging internal resistance has been measured. The charging internal resistance is different and will be determined in later experiments.

\section{Battery Testing}

\section{Experimental Setup}

The three batteries were tested using solar home system 'power hubs' connected to electrical appliances as test loads. The test equipment is shown in Figure 1. In some experiments, the appliance was connected directly to the output of the inverter, but in others it was connected via a Variac auto-tansformer to reduce the voltage and therefore reduce the load. The combination of Variac and appliance thereby became a variable resistor. The Acksen power recorders were validated by comparison with a Yokogawa power analyser in some experiments. The Yokogawa measured AC currents, AC voltages and phase angles, both upstream and downstream of the Variac, whereas the Acksen only measured apparent power. When the load was almost entirely resistive (phase angle $=1.0$ ), the Acksen was found to agree with the Yokogawa to within $1 \%$ accuracy.

The hotplate (manufactured by Sabichi) had a nominal power rating of $1.5 \mathrm{~kW}$, but when connected to a power hub inverter, its maximum power was found to be closer to $1.3 \mathrm{~kW}$ at a voltage of about $230 \mathrm{~V}$.

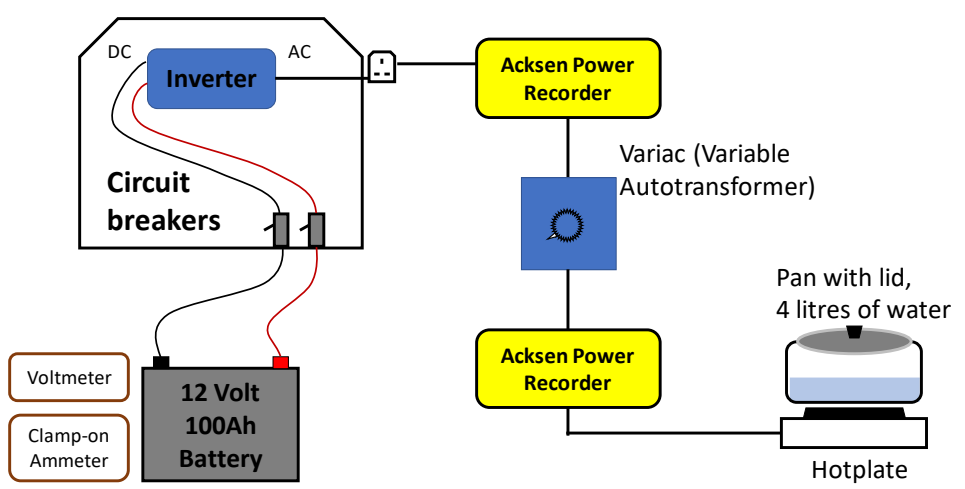

Figure 1. Experimental apparatus for battery testing

\section{Battery Power Calibration with Hotplate power}

For the hotplate to be a useful and quantitative measure of battery output power and cumulative energy output, its power consumption was calibrated by cross-reference to simultaneous measurements of the current and voltage at the battery terminals. This technique was also used, with the Yokogawa, to calculate the efficiency of the power hub (see separate report). The battery power as a function of hotplate power is shown in Figure 2. 


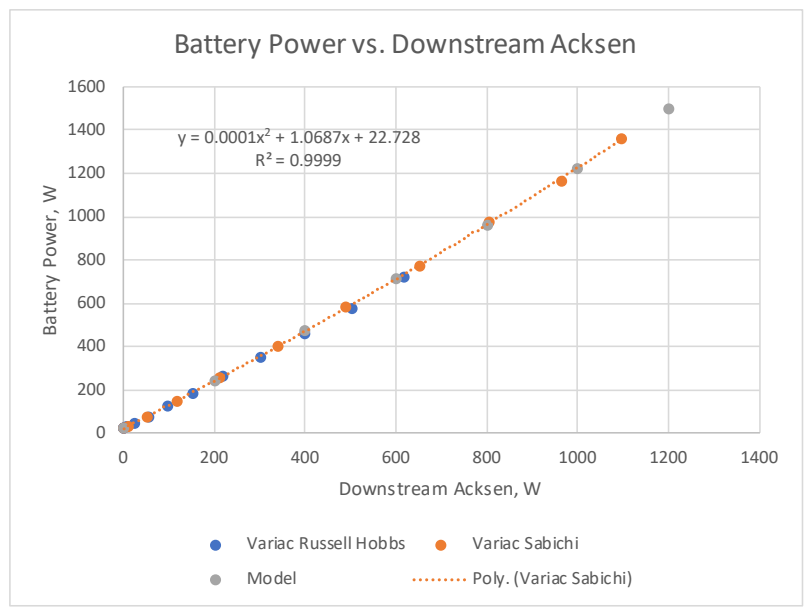

Figure 2. Battery output power vs. hotplate power

\section{Test Procedure}

1. The battery was first subjected to an increasing load by turning on the power hub inverter and setting the Variac to values between $0 \%$ and $100 \%$ in increments of $10 \%$. This was done to measure the fully-charged power capability and the fully-charged internal resistance.

2. The battery was then discharged at the maximum load that did not trip the inverter. A fully charged battery was usually found to be capable of providing up to $1.3 \mathrm{~kW}$ at $100 \%$ Variac setting. This sometimes temporarily tripped out the inverter in 'overload' fault. As the battery was depleted, the inverter again tripped out but this time due to low input voltage. The Variac was then progressively reduced in setting from $100 \%$ to $80 \%, 70 \%, 60 \%$ or even $50 \%$ each time the inverter tripped out. When the inverter quickly tripped out after each reduction in setting, it appeared that the battery was close to voltage collapse and considered almost flat.

3. Finally, the Variac was again set to value between $0 \%$ and $100 \%$ in increments of $10 \%$ until the inverter tripped out. This was done to measure the nearly-flat power capability and the nearly-flat internal resistance.

\section{Test Results}

The typical power output of a battery is shown in Figure 3. The power steps up during the first internal resistance test until the inverter trips out. The steady power endurance test for this battery, the YUASA VRLA, starts at $80 \%$ Variac setting, that being the maximum power delivered by the fully charged battery. The test continues to $70 \%, 60 \%$, and $50 \%$ Variac settings. The final internal resistance test causes the inverter to trip out at a much lower power.

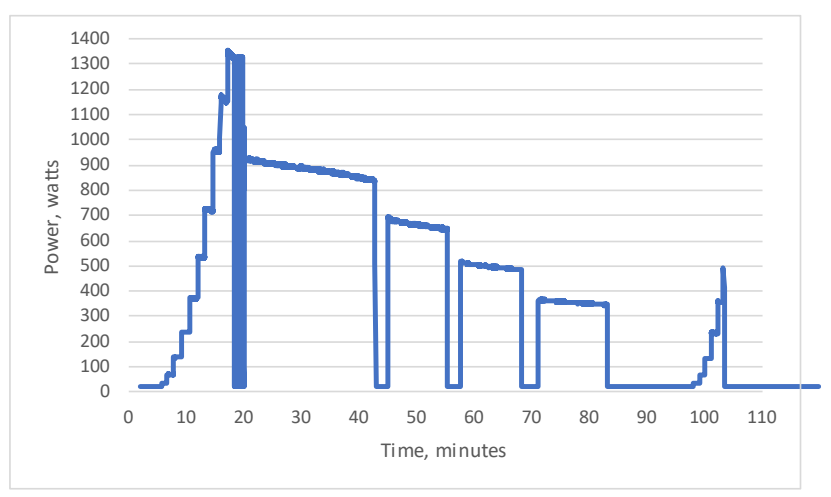

Figure 3. Battery power output profile during the test of the Yuasa VRLA batteries 
The Acksen power recorder on the Variac output was used to measure the cumulative energy available from the battery.

\section{Battery test results compared}

The voltage-current characteristics of all three batteries are compared in Figure 4 . The YUASA VRLA battery has the lowest starting voltage, and dips lowest during the initial power test. The lithiumiron-phosphate battery has the highest voltage, and its voltage remains highest even just before voltage collapse at the end of the final test.

All batteries suffer a drop in voltage at the terminals as they are discharged, firstly due to a drop in the open-circuit voltage. Hence the voltages are reduced when almost flat, even at zero current. The lithium-iron-phosphate battery has a drop in open-circuit voltage of just $0.7 \mathrm{~V}$ whereas the others drop by well over $1 \mathrm{~V}$.
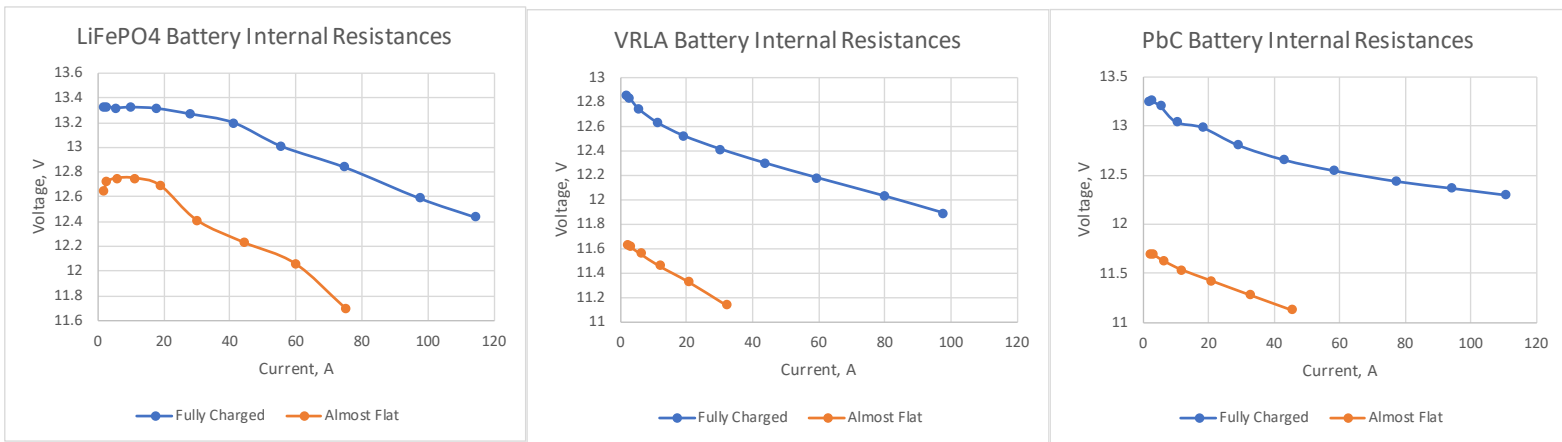

Figure 4. Current-voltage characteristics of three battery types when fully charged and when mostly discharged.

The second reason for a drop in battery terminal voltage is internal resistance. Using the central portions of each test, a linear trendline can be plotted. The gradient of this trendline indicates the internal resistance, Figure 5 . The lithium-iron-phosphate and lead-acid batteries have very similar internal resistances, but the lead-carbon battery has a lower resistance, both at the beginning and end of the discharge test.

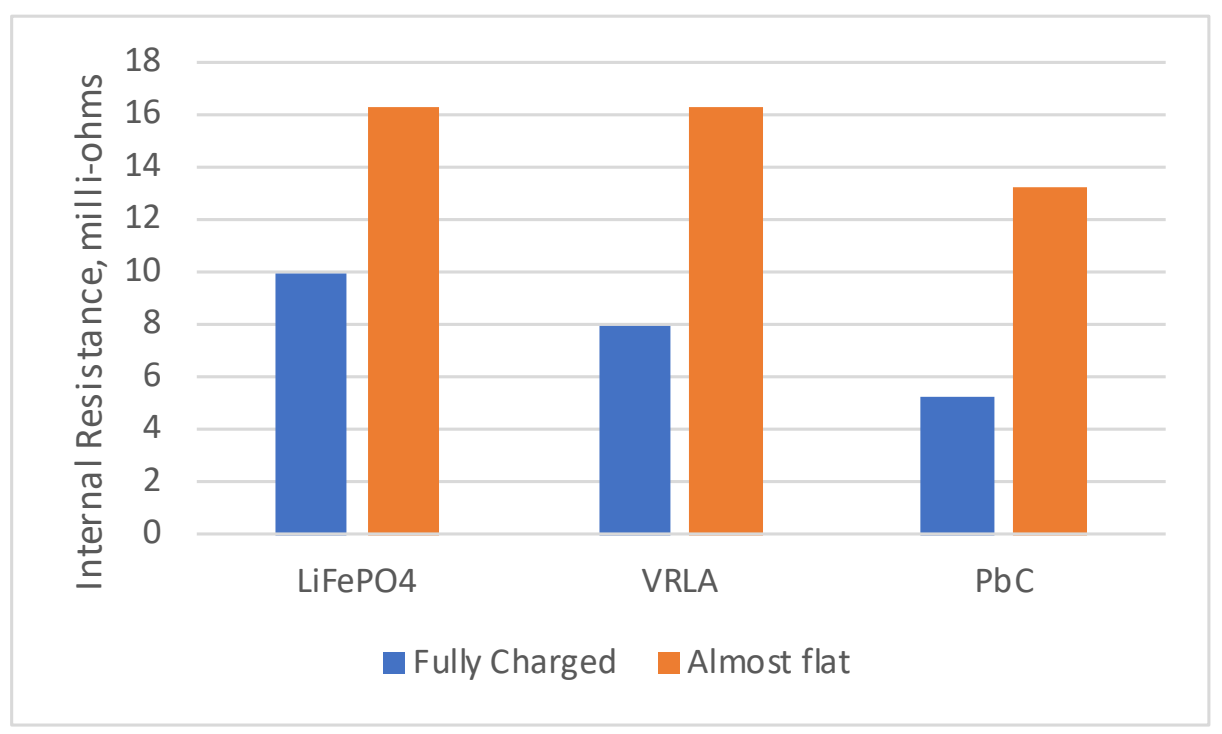

Figure 5. Internal resistances of the batteries 
The total energy extracted from the batteries and final continuous power before voltage collapse are plotted in Figure 6.

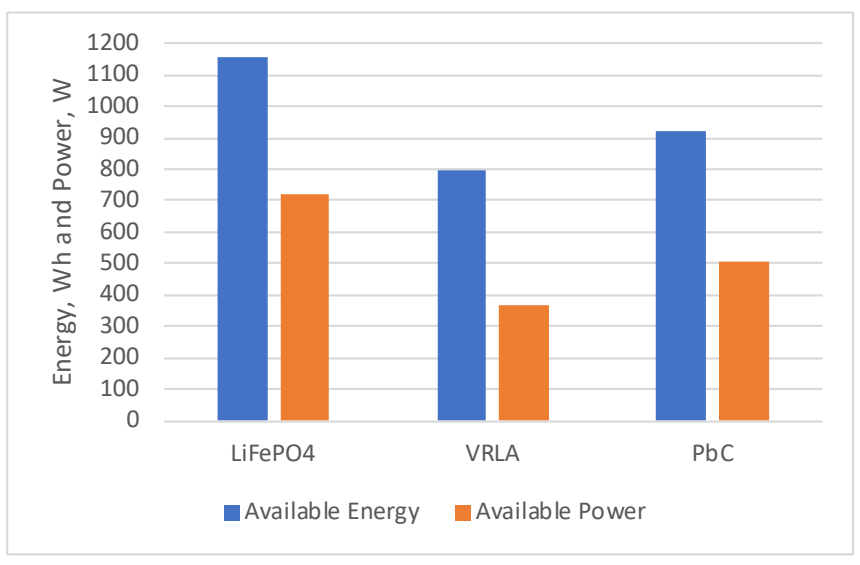

Figure 6. Available energy extracted during the test and power drawn before voltage collapse

\section{Discussion}

Based on the tests above, the lithium-iron-phosphate battery appears better than either of the leadbased chemistries. Only the lithium-iron-phosphate can deliver 700 watts until it is almost flat, and it is the only one to come close to delivering its nominal capacity at $\mathrm{C} / 2$ discharge rate.

However, the power and energy delivery of these nearly new batteries, in their nearly new condition is not the only consideration when choosing a battery for an electric cooking system. Cost, degradation rate (useful cycle life) in real world use and local availability are equally important. Table 1 compares these design considerations. The reported cycle life was supplied by manufacturers. Generally, the greater the Depth of Discharge (DoD) the shorter the life expectancy so the reported values may not reflect real situations.

Table 1. Summary table comparing battery chemistries

\begin{tabular}{|l|l|l|l|l|l|}
\hline Battery type & $\begin{array}{l}\text { Measured } \\
\text { energy output } \\
\text { from 1.2kWh } \\
\text { battery }(\mathrm{Wh})\end{array}$ & $\begin{array}{l}\text { Measured } \\
\text { power from } \\
1.2 \mathrm{kWh} \\
\text { battery }(\mathrm{W})\end{array}$ & $\begin{array}{l}\text { Reported } \\
\text { cycle life } \\
\text { (DoD not } \\
\text { clear) }\end{array}$ & $\begin{array}{l}\text { Operating } \\
\text { temperature } \\
\text { range }\end{array}$ & $\begin{array}{l}\text { Purchase cost } \\
\text { per kWh } \\
\text { See Appendix }\end{array}$ \\
\hline LiFePO4 & 1160 & 718 & $2000[1]$ & $-20 \mathrm{C}$ to $60 \mathrm{C}[2]$ & f640 \\
\hline VRLA & 795 & 365 & $1000[3]$ & $-15 \mathrm{C}$ to $40 \mathrm{C}[3]$ & $\mathrm{f} 130$ \\
\hline PbC & 923 & 504 & $2500[4]$ & $-40 \mathrm{C}$ to $60 \mathrm{C}[5]$ & f210 \\
\hline
\end{tabular}

\section{Conclusions}

Of the three battery chemistries tested, the lithium-iron-phosphate (LiFePO4) is clearly superior to the lead-acid and lead-carbon. It maintains a higher open-circuit voltage and can deliver much more energy at high power. Its energy delivery before voltage collapse is almost the nominal capacity of $1.2 \mathrm{kWh}$. LiFePO4 is the only battery chemistry to deliver up to $700 \mathrm{~W}$ continuously, the required power rating for electric cooking, at a nominal capacity of $1.2 \mathrm{kWh}$.

The lead-carbon battery can deliver up to $500 \mathrm{~W}$ continuously until voltage collapse, the minimum level of power required for electric cooking.

The valve-regulated lead-acid (VRLA) battery has poorer performance and is unsuitable. 
Appendix

\begin{tabular}{|c|c|c|}
\hline Battery & $\begin{array}{l}\text { Unit purchase cost VAT } \\
\text { not included (2019) }\end{array}$ & Cost per Wh \\
\hline $\begin{array}{l}\text { LI50-12, 12V 50AH LITHIUM IRON... (600Wh) } \\
\text { https://www.batterymasters.co.uk/lithium- } \\
\text { phosphate-batteries/li50-12-12v-50ah- } \\
\text { lithium-iron-phosphate-lifepo4-high- } \\
\text { capacity-deep-cycle-battery-charger- } \\
\text { included.html }\end{array}$ & $£ 385.60$ & $64 p$ \\
\hline $\begin{array}{l}\text { PLH+C100 pure lead carbon battery(1.2kWh) } \\
\text { https://batterystore.co.uk/plh-c100-pure- } \\
\text { lead-carbon-series-battery.html }\end{array}$ & $f 250$ & $21 p$ \\
\hline $\begin{array}{l}\text { Ultamax NPG50-12V 50AH (600W) } \\
\text { https://www.batterymasters.co.uk/ultramax- } \\
\text { npg50-12-12v-50ah-as-40ah-45ah- } \\
\text { emergency-light-lighting-gel-battery.html }\end{array}$ & $f 77.78$ & $13 p$ \\
\hline
\end{tabular}

\section{References}

[1] Li50-12, 12v 50Ah Lithium Iron Phosphate, LiFePO4 High Capacity Deep Cycle Battery https://www.batterymasters.co.uk/lithium-phosphate-batteries/li50-12-12v-50ah-lithium-ironphosphate-lifepo4-high-capacity-deep-cycle-battery-charger-included.html

[2] Lithium Iron Phosphate Battery https://www.batteryspace.com/prod-specs/9055.pdf

[3] Gel Battery Technical Manual https://files.elv.com/service/manuals hw/71974 Blei Gel Akku UMenglisch.pdf

[4] PLH+C100 - 12v 100Ah Pure Lead Carbon Series Battery https://batterystore.co.uk/leoch-plh-c100-leisure-battery/

[5] Pure Lead Carbon Technology https://batterystore.co.uk/content/SpecSheets/Leoch/Leisure/PLH/PLHC-100.pdf 